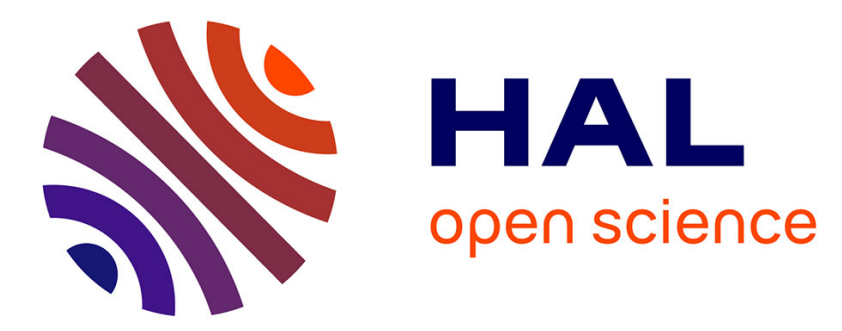

\title{
Nonlinear tensile behaviour of elementary hemp fibres. Part I : Investigation of the possible origins using repeated progressive loading with in situ microscopic observations
}

Vincent Placet, Ousseynou Cisse, Lamine Boubakar

\section{To cite this version:}

Vincent Placet, Ousseynou Cisse, Lamine Boubakar. Nonlinear tensile behaviour of elementary hemp fibres. Part I: Investigation of the possible origins using repeated progressive loading with in situ microscopic observations. Composites Part A: Applied Science and Manufacturing, 2014, 56, pp.319 - 327. hal-02300212

\section{HAL Id: hal-02300212 \\ https://hal.science/hal-02300212}

Submitted on 29 Sep 2019

HAL is a multi-disciplinary open access archive for the deposit and dissemination of scientific research documents, whether they are published or not. The documents may come from teaching and research institutions in France or abroad, or from public or private research centers.
L'archive ouverte pluridisciplinaire HAL, est destinée au dépôt et à la diffusion de documents scientifiques de niveau recherche, publiés ou non, émanant des établissements d'enseignement et de recherche français ou étrangers, des laboratoires publics ou privés. 


\title{
Nonlinear tensile behaviour of elementary hemp fibres. Part I: Investigation of the possible origins using Repeated Progressive Loading with in situ microscopic observations
}

\author{
Vincent Placet,* Ousseynou Cissé, M. Lamine Boubakar \\ FEMTO-ST Institute, Department of Applied Mechanics, UMR CNRS 6174 ,University of Franche-Comté, \\ F-25000 Besançon, \\ *Email: vincent.placet@univ-fcomte.fr \\ tel: +33 (0)3 81666055 fax: +33(0)3 81666700
}

\begin{abstract}
The aim of this study is to achieve a better understanding of the nonlinear tensile behaviour of the elementary hemp fibre. This is of great importance in view of the need to develop an efficient predictive tool for the design of natural fibre reinforced composites. This first paper investigates the possible mechanisms responsible for the nonlinear behaviour, using repeated progressive tensile loading with in situ polarised light microscopy.

The persistence of residual strain has been confirmed during testing when the tensile load was released. Only a certain fraction of this residual strain is reversible, and the reversibility is time-dependent. Beyond the yield level, the fibre's rigidity is not deteriorated, but significantly increased as a function of the number of loading cycles and the level of strain. A new scenario involving a stick-slip mechanism, extension and re-orientation of the microfibrils and shear strain-induced crystallisation of the amorphous cellulose is proposed.
\end{abstract}

Keywords: Hemp fibres, B. Mechanical properties, D. Mechanical testing

\section{INTRODUCTION}

In recent years, due to growing environmental concerns and the depletion and price of oil, there has been a growing renewal of interest in fibres derived from natural sustainable sources, as a result of their potential use in high performance composite materials. Many types of natural fibre have been identified as 
having appropriate mechanical properties for structural applications. Sisal, flax, and hemp are examples of plants with such fibres, however many other suitable fibres exist, especially in emerging countries.

Because natural fibres are characterised by a large variability in their mechanical properties, the design of reliable structures based composites containing such natural fibres is a significant challenge for engineers, who are accustomed to the availability of consistent and accurate data for man-made fibres. In addition to their highly scattered mechanical properties, some differences in the shape of the stress-strain curves can be observed, from one fibre to another. This was revealed in the seventies for the case of wood fibres, by the work of Page and El-Hosseiny [1,2]. The effective tensile behaviour of elementary wood fibres was found to be affected by several parameters, including: mean tilt angle of the cellulose microfibrils relative to the longitudinal cell axis, usually referred to as the microfibril angle (MFA) [2], MFA non-uniformities along the fibre [3], fibre location in the tree stem [4], maturity or juvenility of the fibre [5], and defects [3]. More recently, varyiable tensile behaviour was also observed for hemp bast fibres [6,7], as shown in Fig. 1.a. The first behaviour ('Type 1 ') was shown to be truly linear; the second nonlinear, with a decrease in rigidity above an initial yield point; and the 'Type 3' behaviour was found to present multiple nonlinearities. The origin of these three different behaviours is currently unknown. In the case of hemp, the hypothesis of maturity, or the position of each fibre in the stem, could be considered. Indeed, the fibres used for industrial purposes are composed of primary and secondary fibres, both originating from the phloem. These two distinct types of bast fibre found in hemp have different and independent types of development, and also have different morphological and biochemical compositions [8-10], which could explain their distinctly different mechanical behaviours [11]. To the best of the authors' knowledge, this question has not been examined in the literature and still remains open.

Another moot point is that of the origin of the nonlinear behaviour revealed by most of the stress-strain curves, such as that shown in Fig.1.b, which has been described by several authors as being a characteristic of natural fibres. Indeed, this nonlinear tensile behaviour has been observed by many authors in wood [2,3,1215], and also in plant fibres such as flax [16-18] and hemp [6,7,19]. The first part of this Type 3 curve (I) is apparently linear up until a yield level $\left(i_{1}\right)$, beyond which a strong decrease in rigidity is observed (II). A second inflection point $\left(i_{2}\right)$ appears at a higher deformation, and is followed by a quasi-parabolic increase in rigidity up until final failure (III). In the past, the origin of this nonlinear behaviour could be explained for 
certain elementary types of fibre. In the case of wood tracheids, Page et al. [1] confirmed a relationship between the nonlinear shape of the tensile curve and the onset of cell wall buckling. Nonlinear behaviour is also frequently attributed by other authors to reorientations of the cellulose microfibrils with respect to the fibre axis, when they are submitted to axial loading. A linear fit was established between MFA and strain for coir fibres, by Martinschitz et al. [20]. Others authors attribute this nonlinear behaviour to shear deformations in the non-crystalline region, which can partially damage the cell wall [21], or to a stick-slip phenomenon [15]. The nonlinear tensile behaviour of hemp fibres was modelled by Nilsson and Gustafsson [22], by introducing defects into the helical structure of the cellulose microfibrils, and by Navi and Sedighi-Gilani $[3,23]$ who proposed a model for wood fibres with an elasto-plastic behaviour for amorphous polymers, based on the assumption of a helical, non-uniform distribution of cellulose microfibrils in the fibre and damage of the amorphous constituents after yielding.

The development of accurate micro-mechanical models requires a precise understanding of the changes in fibre ultrastructure and macromolecular arrangement which occur under axial loading. The aim of our study was to improve the characterisation, and investigate the origin, of the nonlinear tensile behaviour of hemp fibres. This first paper (Part I) proposes an experimental approach, using repeated progressive loading (RPL) and in situ optical observations in order to provide a substantiated discussion of state-of-the-art hypotheses.

\section{EXPERIMENTAL METHOD}

\section{Plant material}

Hemp fibres (Cannabis sativa L.) were procured from the LCDA Company in France. They were delivered in a jumbled state. Bundles of fibres were washed in water at $30^{\circ} \mathrm{C}$ for $72 \mathrm{~h}$, as recommended by Bourmaud et al. [24], to facilitate the extraction of elementary fibres. Elementary fibres were isolated by hand and only untwisted fibres were selected. To facilitate and simplify their handling, thin paper with glue was used to form mounting tabs.

Ten fibres were also cut into two parts approximately $5 \mathrm{~mm}$ in length. This made it possible to run tests by varying one parameter, and to compare the results without being affected by the uncertainties arising from the strong variations in mechanical properties produced when a set of fibres is used. The fibres were cut using a 
microtome blade and glued on the paper frame over a distance of $1 \mathrm{~mm}$ at each extremity to prevent the gauge part of the fibre from any major damages that could occur during the cutting.

\section{Optical microscopy examination}

The isolated single fibres were firstly examined using polarised light microscopy (Nikon Eclipse LV 150), to determine their outer diameters and detect the possible presence of defects or twists in the fibre. The average diameter of each fibre was computed by taking ten measurements along its length. The effective cross-sectional area was calculated from this average diameter, assuming the fibre to be perfectly cylindrical. This approximation certainly introduces a systematic error but does not change qualitatively the observed behaviour. Some observations were also performed in situ during tensile testing.

\section{Tensile test on elementary fibres}

\section{RPL (Repeated Progressive Loading)}

A Dynamic Mechanical Analyser (Bose Electroforce 3230) was used to perform one batch of the tensile tests. Ten elementary fibres were submitted to repeated, progressive tension loading cycles, at a loading rate of 0.3 $\mathrm{mN} . \mathrm{s}^{-1}$, which was increased by $20 \mathrm{mN}$ at each successive cycle, until the fibre's failure. The clamping length was $10 \mathrm{~mm}$. In accordance with the ASTM standard, the paper frame supporting each elementary fibre was clamped onto the testing machine, and was cut before initiating each test. Some additional tests were also performed, with 5 to 10 cycles at a constant amplitude during each loading step. Some other fibres were finally tested using RPL, with a pause time between each cycle during which the load was released. The pause time varied from several seconds to a few hours. For these two last experiments, three to five replicates were used in order to confirm the results we present here.

The apparent tensile stress was determined using the cross-section of each fibre and the strain computed from the crosshead displacement. The apparent Young's modulus was computed from the first linear section of the stress-strain curve in the reloading phase. The compliance of the loading frame was not taken into account; the stiffness of the test set-up was measured at least 100 times higher than the typical fibre's stiffness.

\section{Home-made micro-tensile stage with in situ observation of deformations and dislocations}

Several fibres were also tested on a home-made micro-tensile stage, with in situ optical observations (Fig. 2). The stage was designed to be relatively compact $\left(20 \times 20 \times 100 \mathrm{~mm}^{3}\right)$, allowing it to be easily positioned on a 
microscope sample holder such that the microscope objective could be brought into position, above the fibre at the appropriate working distance for the objective. Magnifications of up to x 100 could be used.

The stage was designed to apply loads and perform measurements on fibres between one and approximately ten millimetres in length, and having a diameter of a few tens of microns. A linear piezoelectric micromotor with a maximum capacity of $2 \mathrm{~N}$, a maximum stroke of $7 \mathrm{~mm}$ and a resolution of $0.5 \mu \mathrm{m}$ (SQL-3.4-10 New Scale Technologies), was used to load the sample. The displacement of the jaws was measured using a miniature contact-less magnetic sensor (NSE-5310 Tracker New Scale Technologies) with a resolution of $0.5 \mu \mathrm{m}$. The fixed jaw was connected directly to a load sensor. This home-made extensometric sensor is mounted on a full bridge and has a measuring range of $2 \mathrm{~N}$. The sample was confined within an enclosure, in which the relative humidity can be controlled by means of a HumiSys apparatus (Instruquest), over the range between $10 \%$ and $85 \%$. An XYZ stage was also mounted on the mobile part of the machine, to allow the fibre to be correctly positioned and aligned. The clamp on this mobile part could be allowed to rotate about their axis, in order to twist or untwist the fibre before carrying out any tensile tests. A toohed wheel allows the rotation to be locked during the tensile test, and a vernier to measure the angle of rotation.

Ten elementary fibres were subjected to RPL, using a crosshead displacement velocity of $1.5 \mu \mathrm{m} . \mathrm{s}^{-1}$ and a clamping length of approximately $3 \mathrm{~mm}$. The length was measured for each fibre before test using the optical microscope. The strain is calculated using the measured initial length. For the ten other fibres, one half was tested without twisting, and the other half was tested after having twisted the fibre by one or two full turns in the counter-clockwise direction.

The tests were carried out at a controlled temperature of $23.5^{\circ} \mathrm{C} \pm 1.5^{\circ} \mathrm{C}$ and a relative humidity of $25 \% \pm 5 \%$, both on the commercial apparatus and the home-made tensile stage.

\section{RESULTS}

During tensile loading and unloading the stress-strain curves are quasi-linear up to the yield point (Fig. 1a point $\left(i_{1}\right)$ ), as shown in Figs. 1 and 3. Beyond this point, the apparent rigidity of the fibre decreases significantly when the fibre is loaded. When the load is released, the fibre's stiffness is not only recovered but significantly increased. When the fibre is re-loaded, the curve remains linear up to the previously applied 
maximum loading level, and then deviates again in accordance with a lower apparent rigidity beyond this point. These RPL tests clearly show that the level of the yield point $i_{1}$ increases after each additional progressive loading phase. These experimental results also reveal the persistence of residual strain when the tensile load is released, regardless of the loading level. The residual strain accumulates as a function of the applied loading cycles (Fig. 3).

Fig. 4 illustrates the increase in stiffness after each progressive re-loading, for the different tested fibres. Ten isolated fibres were initially tested. Six fibres exhibited a type 3 stress-strain curve. This proportion is in agreement with that measured in a previous study at this level of ambient relative humidity [7]. The normalized Young's modulus progressively increases with RPL until it reaches a remarkable value between 2 and 3.8, depending on the individual fibre. To check that this increase in modulus was not due to the compliance of the machine or to the glue at the extremity of the paper frame, the same tests were performed on metallic yarns. No stiffness increase was observed.

The reversibility of the residual strain was checked by introducing a pause time following load release, for each cycle. Fig. 5 shows the stress-strain curves recorded for pause times of 30 min and 3 hours between each loading cycle. It can clearly be seen in Figs. 3 and 5 that the hysteresis occurring between load release and subsequent loading increases as a function of the pause time. This outcome demonstrates that, although a major component of the residual strain is permanent and irreversible, a minor component is time dependently reversible. Irreversible strains are measured even when the fibre is loaded below the yield point (Fig. 6). In the case of a constant loading level, additional strain is accumulated during each cycle. Tab. 1 provides a summary of the values of irreversible and recovery strains, following $3 \mathrm{~h}$ of load release, as a function of cycle number during RPL testing. The strain recovery varies from $0.03 \%$ to $0.14 \%$, depending on the initial level of strain. The total irreversible strain at the ultimate tensile loading is approximately $1.45 \%$, whereas the total recovered strain is approximately $0.5 \%$ when this tensile loading is reached. Tab. 2 gives the values of the apparent Young's modulus for each loading and unloading step, for this same test. The stiffening is clearly relaxed during the pause time, i.e. when the fibre is not loaded. The decrease in stiffness between the unloading step and the next loading step varies from 1 to $25 \%$, depending on the level of strain. This relaxation of the stiffening phenomenon is particularly pronounced when the fibre is tested in the second part of the tensile curve (II). 
Experimental tests with repeated constant amplitude loading also show that the stiffening phenomenon is even more significant when the level of strain increases, in particular when the strain level exceeds the yield point (Fig. 6a). Fig. 6b shows that, below the yield point, the apparent Young's modulus increases by approximately $8 \%$ after 10 cycles at the same loading level. This stiffening phenomenon resulting from repeated low loading levels has been widely studied [25,26]; we showed that the rigidity increases by as much as $60 \%$ after a few thousand cycles, and tends to stabilize even when a higher number of cycles is applied. In this study, we show that when the yield point is exceeded, the fibre stiffness can be increased by almost $20 \%$ in a single cycle. The stiffening rate as a function of cyclic loading at constant maximum stress is then at least twice as high as for the case of loading below the yield point (Fig. 6b).

The aforementioned tensile behaviour and stiffening phenomena are also shown to be influenced by twisting of the fibre (Figs. 7, 8). Indeed, wood or plant fibres with a z-helix orientation of the S2 layer cellulose microfibrils are known to adopt an anti-clockwise rotation when they are dried [7,27,28]. To investigate any possible influence of microfibril twisting on the shear strain and tensile behaviour of hemp fibres, several isolated fibres were cut into two pieces, one of which was twisted with one or two full turns in the counter-clockwise direction, before being subjected to the RPL test (Fig. 7). The stress-strain curves obtained on the twisted and untwisted sections of the fibre are compared in Fig. 8, and the normalized Young's moduli expressed as a function of cycle number are listed in Tab. 3. These results indicate a significant shift of the yield point towards a lower value of strain in the case of the twisted fibres, leading to an additional increase in stiffness of approximately 4 to $11 \%$ for each of the initial cycles of RPL. Twisting could induce modification of the cell wall structure.

In the third domain of the stress-strain curve, the relationship between stress and strain is slightly parabolic (Fig. 1b). Images recorded using polarised light microscopy at different loading levels clearly show that the dislocations gradually disappear from the hemp fibre during tensile testing (Fig. 9a). This result is in agreement with the work of Thygesen et al. [29]. In the present study it was also found that the dislocations disappeared only beyond the second inflection point $\left(\mathrm{i}_{2}\right)$, as shown in Fig. 10. Dislocations are zones in the fibre in which the cell wall MFA is greater than in most other parts of the fibre. Beyond the stress level 
corresponding to the second inflection point, the cellulose microfibrils in these distorted areas are in all likelihood rotated to an orientation which is nearly parallel to the fibre axis, such that their MFA becomes very similar to that of the surrounding areas, and no obvious difference in surface reflectivity can be observed under polarised light. This deployment of the microfibrils in the dislocation areas is partially reversible, since the dislocations reappear a few minutes after the load has been released (Fig. 9.b). As emphasized by Thygesen et al. [29], the straining of dislocations does not lead to a new stable condition. This reversibility is highly time-dependent, and the time constant was determined to be relatively short when compared with the value of two months reported by the above authors.

\section{DISCUSSION}

Many hypotheses have been proposed in the literature to explain the nonlinear tensile behaviour of isolated wood or plant fibres, and the fibres' stiffness recovery or improvement after loading beyond the yield point. The aim of the present paper is to discuss the validity of these different hypotheses for elementary hemp bast fibres, in view of the measurements and in situ observations made during our RPL tests.

\section{$\underline{\text { State-of-the-art hypotheses }}$}

\section{(i) Cell wall buckling}

Wall buckling can occur under tension in anisotropic cylinders, such as helically-wound composite tubes. This was revealed in the sixties by Pagano and Halpin [30], for the case of tubular composites. Using analytical and experimental investigations, they demonstrated that this phenomenon strongly depends on the wall thickness and boundary conditions. Wall buckling was also observed for wood fibres by Page and ElHosseiny [2] and Eder et al. [28]. They clearly showed that for thin-wall cells, the yield point $\left(\mathrm{i}_{1}\right)$ corresponds to the onset of wall buckling. They also showed that thick-walled fibres are highly resistant to tension buckling. In agreement with these results, since hemp fibres generally have a thick wall with a small lumen [31], no wall buckling was observed during the tensile tests on isolated hemp bast fibres. Tension buckling therefore does not explain the nonlinearity of the stress-strain curve in the case of hemp bast fibres.

\section{(ii) Cellulose microfibril re-alignement}

The apparent fall in the fibres' stiffness in the second part (II) of the stress-strain curve is often attributed to reorientation of the cellulose microfibrils with respect to the fibre axis, when they are submitted to axial 
loading $[6,16,18,21]$. This assumption certainly needs to be qualified, since although in situ polarised light microscopy confirmed the microfibrils' re-alignment, this occurred mainly in the dislocation areas, and then only beyond the second inflection point $\left(i_{2}\right)$. Although our results concerning the MFA should be interpreted with considerable caution, since the PLM observations were concerned mainly with the microfibrils on cell wall surfaces, this finding also appears to be confirmed by X-ray observations: a slight decrease in the mean MFA was also measured using in situ X-ray scattering, although mainly in the first part of the stress-strain curve [32-36]. Moreover, since the typical MFA for hemp fibres is close to $10^{\circ}$ [33], it can be shown using theoretical tools [31] that complete re-orientation of the cellulose microfibrils to an angle equal to $0^{\circ}$ would not be sufficient to explain, alone, the considerable increase, by as much as $380 \%$, in experimentally observed stiffness. Additional experiments using in situ synchrotron radiation on elementary hemp fibres are needed to accurately monitor and quantify the evolution of the MFA as a function of tensile stress and strain. This type of experiment, with full-field measurements of microfibril orientations in the fibre, could also confirm or invalidate the hypothesis proposed by Seghini-Gilati and Navi $[3,23]$, i.e. that the stress-strain nonlinearity could be induced by MFA non-uniformities.

\section{(iii) Shear strain of the amorphous polymer}

It is well-known that the elongation of the fibre induces shear strain inside the cell wall, between the cellulose microfibrils and in the matrix between the cellulose microfibrils $[1,15,21,27,28]$. This shear strain leads to longitudinal torsion of the fibre.

\section{Stick-slip mechanism}

Keckes et al. [15] explained the irreversible strain of tensile tested wood fibre by means of a stickslip mechanism, based mainly on this shearing effect in the amorphous matrix. According to these authors, beyond the yield point $\left(i_{1}\right)$ the shear stress could provoke a viscous flow of the matrix. When the stress is released there would be no back-flow of the matrix, but a lock-in phenomenon associated with immediate bond re-formation in the fibrils' new position. This could explain irreversible strain without significant damage. In the case of hemp fibres, in the present study we have shown that in addition to irreversible strain, the fibre's rigidity is not only maintained, but significantly increased. If the microfibrils' re-orientation is not the cause of this stiffening or hardening of the fibre, one could ponder the possibility of a certain degree of crystallisation in the strained amorphous matrix. Indeed, a previous theoretical study clearly emphasised the 
high sensitivity to MFA of the apparent Young's modulus of hemp fibres, and also to the fraction of crystalline cellulose and the shear modulus of the amorphous components surrounding the microfibrils [31].

\section{$\underline{\text { Strain-induced crystallisation }}$}

Using SAXS and WAXS, Astley and Donald [35] showed that with in situ deformation of flax fibres, the (200) peak intensity increases during deformation. This effect was attributed to strain-induced crystallization of the cellulose. According to these authors, this provides evidence that the non-crystalline cellulose chains are initially oriented, and could clearly explain an increase in the fibres' stiffness. Once again, this could be confirmed in the case of hemp fibres, through the use of sophisticated techniques such as in situ synchrotron radiation.

\section{$\underline{\text { Proposed scenario }}$}

On the basis of the experimental results recorded during this study coupled with state-of-the-art knowledge, a new scenario can be proposed to explain the complex tensile behaviour of hemp fibre, as summarised in Tab. 4 and Fig. 11. This scenario provides a basis for discussion, on a subject which remains largely open in the literature. The results of the present study will be enhanced in the near future, through the use of additional experimental and theoretical methods. In the first part of the typical stress-strain curve (I), the linear behaviour is often attributed to the elastic deformation of the fibres' semi-crystalline and amorphous constituents. As shown by our measurements, irreversible strain is clearly present, even at these low loading levels. The elastic deformation of the constitutive polymers is certainly balanced by microstructural re-arrangements, such as straightening of the cellulose microfibrils, which could lead to the observed residual strain effects. Using in situ investigations, Kölln et al. [36] implemented synchrotron radiation to demonstrate that the microfibrils in flax fibres rotate during the first percent of stretching, thereby attaining a more parallel orientation with respect to the fibre axis. In a recent study, we observed the same behaviour in bundles of hemp fibres [34], with a reduction in MFA by approximately $1.5^{\circ}$ in the first domain (I) of the tensile curve. As proposed by Keckes et al. [15], beyond the yield point $\left(i_{1}\right)$ the shear stress in the fibre wall could provoke viscous flow in the matrix, with lock-in occurring at the new position, which could provide an explanation for the irreversible strain and significant decrease in fibre stiffness in the second part of the stress-strain curve (II). This re-arrangement of 
the bonds between amorphous macromolecules does not deteriorate the mechanical properties of the amorphous matrix. The combination of shear strain induced by twisting of the fibre, with tensile strain, clearly lowers the matrix flow threshold. The shear strain affects not only the amorphous polymers, but also the interface between the cellulose microfibrils and the paracrystalline cellulose, as well as the interface between the microfibrils themselves. Paracrystalline cellulose could partially crystallise beyond the yield point, and up to the second inflection point, which possibly corresponds to the crystallisation saturation point. Clearly, this strain-induced crystallisation leads to irreversible stiffening of the fibre in the axial direction. The timereversible fibre stiffening component is attributed to extension of the cellulose microfibrils, much like that of a spiral spring [21], in the amorphous matrix. In the last part of the tensile curve (III), the aforementioned mechanisms are associated with significant and reversible re-alignment of the cellulose microfibrils in the dislocation zones. 


\section{CONCLUSIONS}

Our RPL tests highlight several fundamental aspects of the tensile behaviour of elementary hemp bast fibres, and provide clues to the possible origin of the stress-strain curve nonlinearity. These fundamentals are particularly necessary and useful for the development of suitable micromechanical models.

To summarise, when placed under tensile loading, hemp fibres exhibit:

- Residual strain, which represents up to $2 \%$ at the ultimate load.

These residual strains are accumulated over successive loadings and are even more significant than the increases in loading level applied during each successive cycle.

- Increasing stiffness with increasing strain.

The normalized apparent Young's modulus reaches a value ranging between 2 and 4, as a function of the fibres at their ultimate strain.

- Partial reversibility of the residual strain, and an increase in stiffness as function of the duration of load release.

- Deployment of the cellulose microfibrils in the dislocation zones, in the third domain of the tensile test curves.

Our paper also proposes a new scenario based on microstructural rearrangements. These hypotheses will be tested in the near future, using sophisticated experiments such as in situ X-ray scattering. The results will be published in a second paper.

\section{ACKNOWLEDGMENTS}

The authors would like to thank Camille Garcin, Eric Joseph and Jean-Marc Côte from the FEMTO-ST institute for their assistance with the design and development of the home-made micro-tensile stage.

\section{REFERENCES}

1. Page DH, El-Hosseiny F, Winkler K. Behaviour of single wood fibres under axial tensile strain. Nature 1971;229:252-253.

2. Page DH, El-Hosseiny F. The mechanical properties of single wood pulp fibres. Part VI. Fibril angle and the shape of the stress-strain curve. J Pulp Pap Sci. 1983 september.

3. Sedighi-Gilani M. A micromechanical approach to the behavior of single wood fibers and wood fracture at cellular level. PhD Thesis, EPFL Lausane, 2006. 
4. Groom L, Shaler S, Mott L. Mechanical properties of individual southern pine fibers. Part III: Global relationships between fiber properties and fiber location within an individual tree. Wood Fiber Sci 2002; 34(2):238-250.

5. Mott L, Groom L, Shaler S. Mechanical properties of individual southern pine fibers. Part II: Comparison of earlywood and latewood fibers with respect to tree height and juvenility. Wood Fiber Sci 2002; 34(2):221-237.

6. Duval A, Bourmaud A, Augier L, Baley C. Influence of the sampling area of the stem on the mechanical properties of hemp fibers. Mater Lett 2011;65:797-800.

7. Placet V, Cisse O, Boubakar L. Influence of environmental relative humidity on the tensile and rotational behavior of hemp fibres. J Mater Sci 2012;47:3435-3446.

8. Crônier D, Monties B, Chabbert B. Structure and chemical composition of bast fibers isolated from developing hemp stem. J Agric Food Chem 2005;53:8279-8289.

9. Mediavilla V, Leupin M, Keller A. Influence of the growth stage of industrial hemp on the field formation in relation to certain fibre quality traits. Ind Crop Prod 2001;13:49-56

10. Blake AW, Marcus SE, Copeland JE, Blackburn RS, Knox JP. In situ analysis of cell wall polymers associated with phloem fibre cells in stems of hemp, Cannabis sativa L. Planta 2008;228:1-13

11. Pickering KL, Beckermann GW, Alam SN, Foreman NJ. Optimising industrial hemp fibre for composites. Compos Part A 2007;38:461-468

12. Navi P, Heger F. Comportement thermo-hydromécanique du bois. Presses polytechniques et universitaire romandes, 2005.

13. Navi P, Rastogi K, Gress V, Tolou A. Micromechanics of wood subjected to axial tension. Wood Sci Technol 1995;29:411-429.

14. Burgert I, Eder M, Frühmann K, Keckes J, Fratzl P, StanzlTschegg S. Properties of chemically and mechanically isolated fibres of spruce (Picea abies [L.] Karst.). Part 3: Mechanical characterisation. Holzforschung 2005;59:354-357.

15. Keckes J, Burgert I, Frühmann K, Müller M, Köll, K, Hamilton M, Burghammer M, Roth SV, Stanzl-Tschegg S, Fratzl P. Cell-wall recovery after irreversible deformation of wood. Nature Materials 2003;2:810-814.

16. Baley C. Analysis of the flax fibres tensile behaviour and analysis of the tensile stiffness increase. Compos: Part A 2002;33:939-948.

17. Aslan M, Chinga-Carrasco G, Sorensen BF, Madsen B. Strength variability of single flax fibres. J Mater Sci 2011;46:6344-6354.

18. Charlet K. Contribution à l'étude de composites unidirectionnels renforcés par des fibres de lin : relation entre la microstructure de la fibre et ses propriétés mécaniques. $\mathrm{PhD}$ thesis, 2008.

19. Placet V. Characterization of the thermo-mechanical behaviour of hemp fibres intended for the manufacturing of high performance composites. Compos: Part A 2009;40:1111-1118.

20. Matinschitz KJ, Boesecke P, Garvey CJ, Gindl W, Keckes J. Changes in microfibril angle in cyclically deformed dry coir fibers studied by in-situ synchrotron X-ray diffraction. J Mater Sci 2008;43:350-356.

21. Hearle JWS. The fine structure of fibres and crystalline polymers - Interpretation of the mechanical properties of fibres. J Appl Polym Sci 1963;7:1207-1223.

22. Nilsson T, Gustafsson PJ. Influence of dislocations and plasticity on the tensile behaviour of flax and hemp fibres. Compos: Part A 2007;38:1722-1728.

23. Sedighi-Gilani M, Navi P. Experimental observations and micromechanical modeling of successivedamaging phenomenon in wood cells' tensile behavior. Wood Sci Technol 2007;41:69-85.

24. Bourmaud A, Morvan C, Baley C. Importance of fiber preparation to optimize the surface and mechanical properties of unitary flax fiber. Ind Crop Prod 2010;32:662-667. 
25. Placet V. Characterization of the thermo-mechanical behaviour of Hemp fibres intended for the manufacturing of high performance composites. Compos Part A 2009;40:1111-1118.

26. Placet V. Tensile behaviour of natural fibres. Effect of loading rate, temperature and humidity on the « accommodation » phenomena. 14th International Conference on Experimental Mechanics, Poitiers, France, July 4-9, 2010.

27. Burgert I, Frühmann K, Keckes J, Fratzl P, StanzlTschegg S. Properties of chemically and mechanically isolated fibres of spruce (Picea abies [L.] Karst.). Part 2: Twisting phenomena. Holzforschung 2005;59:247-251.

28. Eder M, Stanzl-Tschegg S, Burgert I. The fracture behavior of single wood fibres is governed by geometrical constraints: in situ ESEM studies on three fibre types. Wood Sci Technol 2008;42:679689.

29. Thygesen LG, Eder M, Burgert I. Dislocations in single hemp fibres-investigations into the relationship of structural distortions and tensile properties at the cell wall level. J Mater Sci 2007;42:558-564.

30. Pagano NJ, Halpin JC. Tension buckling of anisotropic cylinders. J Compos Mater 1968; 2(2):154167.

31. Placet V, Trivaudey F, Cisse O, Guicheret-Retel V, Boubakar ML. Diameter dependence of the apparent tensile modulus of hemp fibres: a morphological, structural or microstructural effect? Compos: Part A 2012; 43:275-287.

32. Thuault A. Approche multi-échelle de la structure et du comportement mécanique de la fibre de lin. PhD thesis, University of Caen, 2011.

33. Placet V, Bouali A, Perré P. The possible role of microfibril angle of Hemp fibre during fatigue tests and its determination using Wide-Angle X-ray diffraction. Matériaux \& Techniques 2011;99:683689

34. Placet V, Bouali A, Garcin C, Cote JM, Perré P. Suivi par DRX des réarrangements microstructuraux induits par sollicitations mécaniques dans les fibres végétales tirées du chanvre. $20{ }^{\text {ème }}$ Congrès Français de Mécanique, Besançon, 2011.

35. Astley OM, Donald AM. The tensile deformation of flax fibres as studied by X-ray scattering. J Mater Sci 2003;38:165-171.

36. Kölln K, Grotkopp I, Burghammer M, Roth SV, Funari SS, Dommach M, Müller M. Mechanical properties of cellulose fibres and wood. Orientational aspects in situ investigated with synchrotron radiation. J Synchrotron Radiat 2005;12:739-744. 

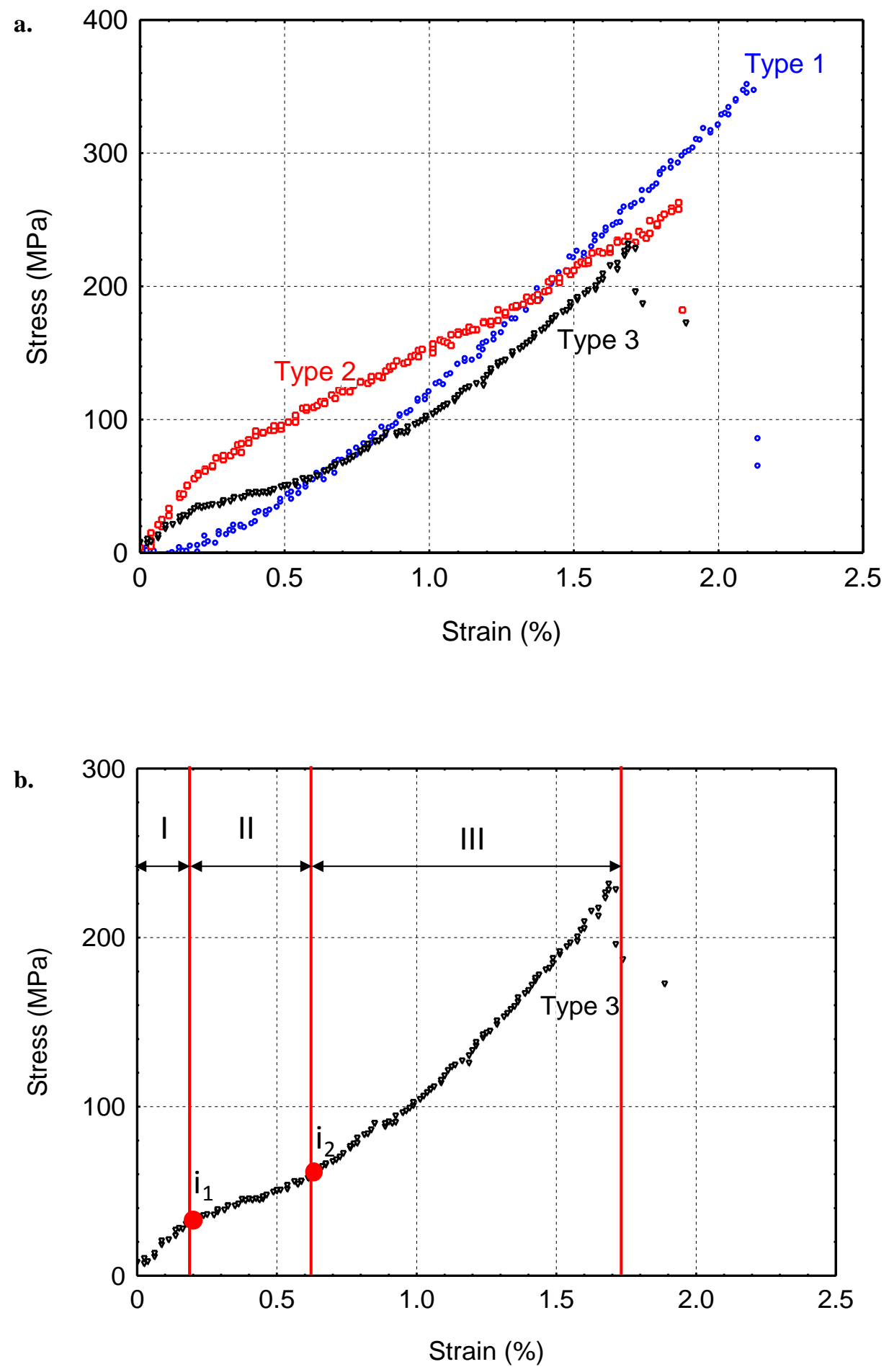

Figure 1. a. The three typical tensile stress-strain curve shapes for elementary hemp fibres, as reported by [7]. b. Type 3 stress-strain curve divided into 3 distinct domains. 


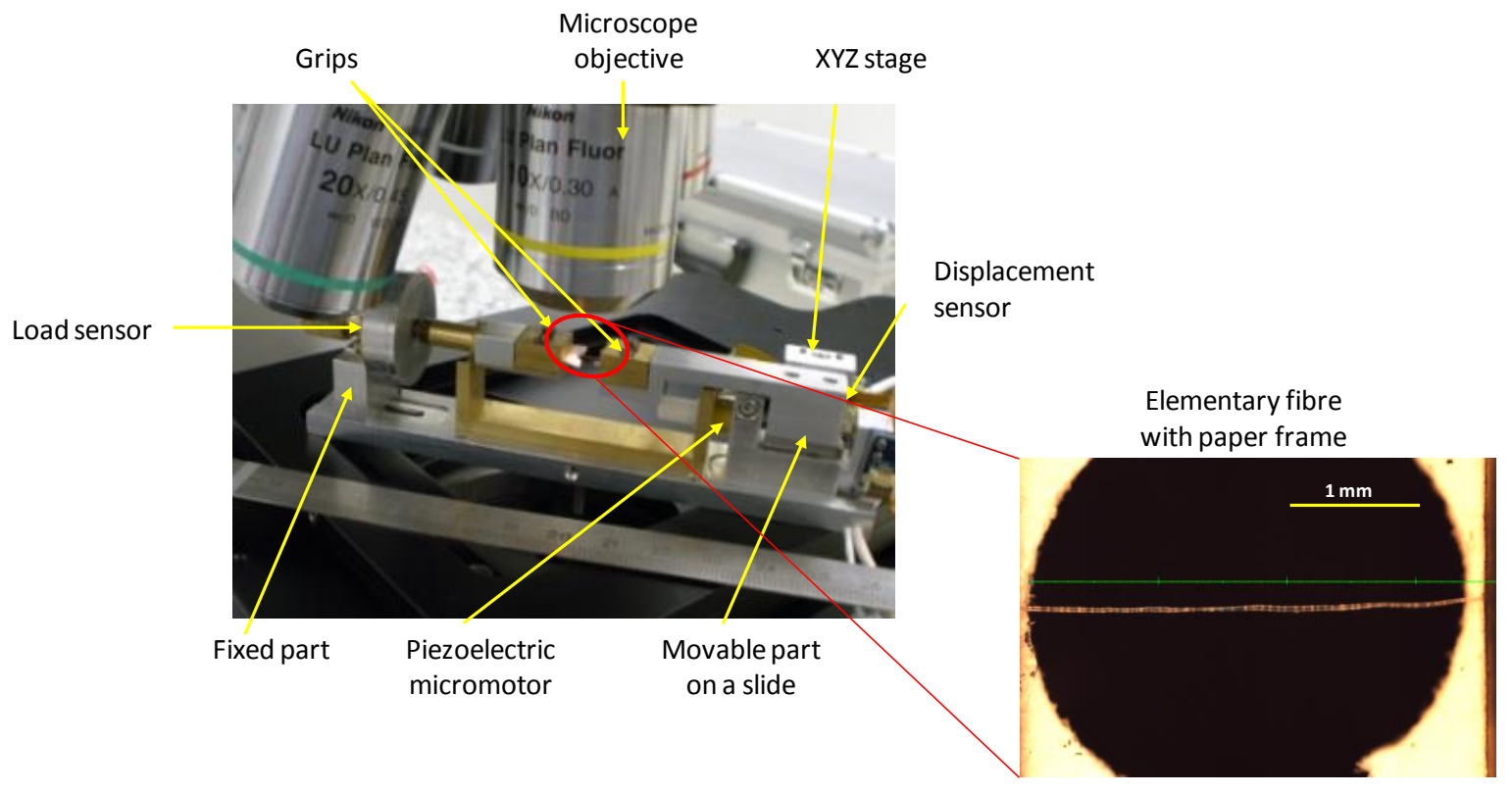

Figure 2: Home-made micro-tensile stage 


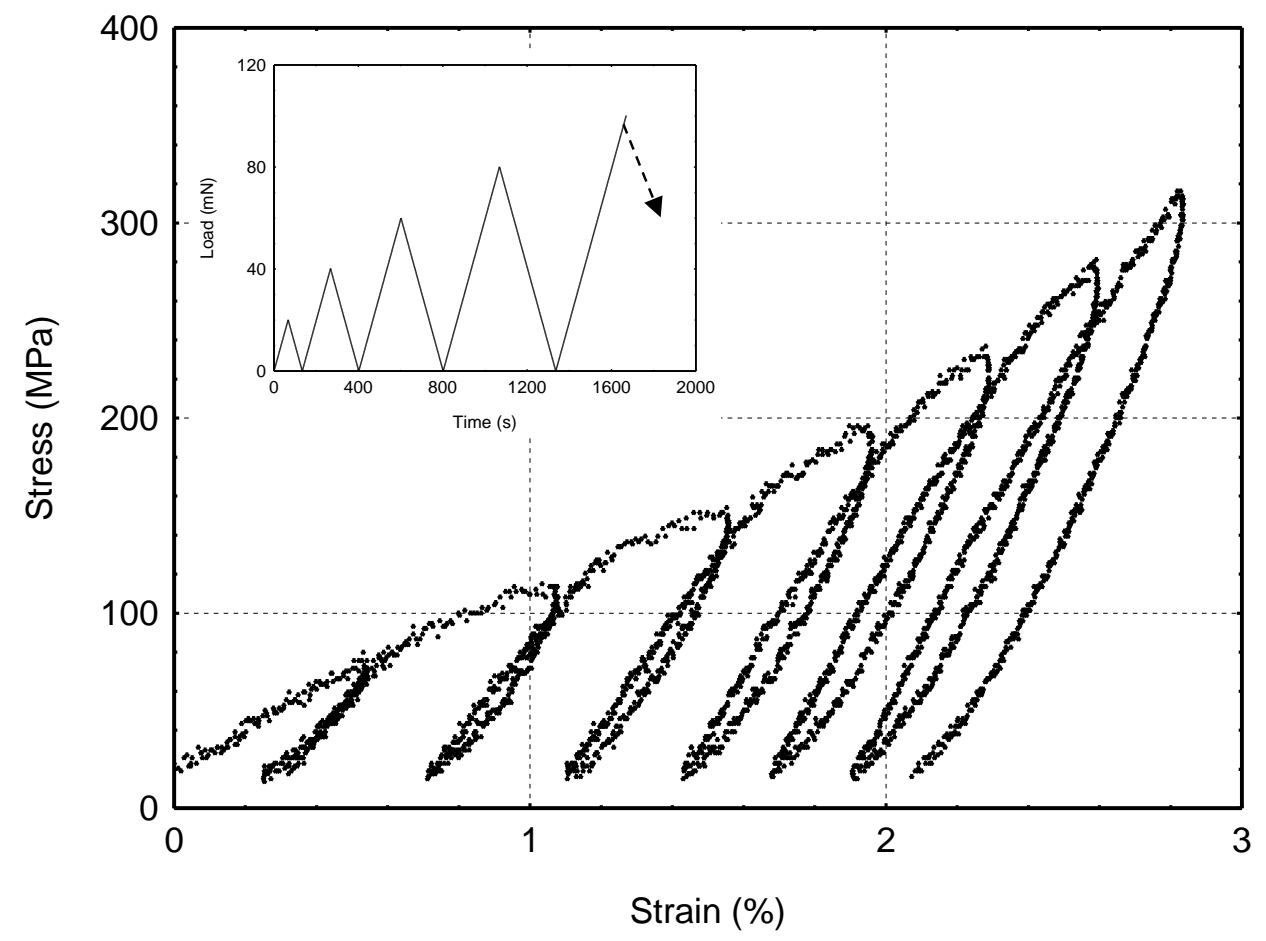

Figure 3: Stress-strain curves resulting from repeated progressive tensile loading of elementary hemp fibres, characterised by residual strain and progressively increasing stiffness as a function of the level of applied stress. (DMA; fibre length: $10 \mathrm{~mm}$; load feedback)

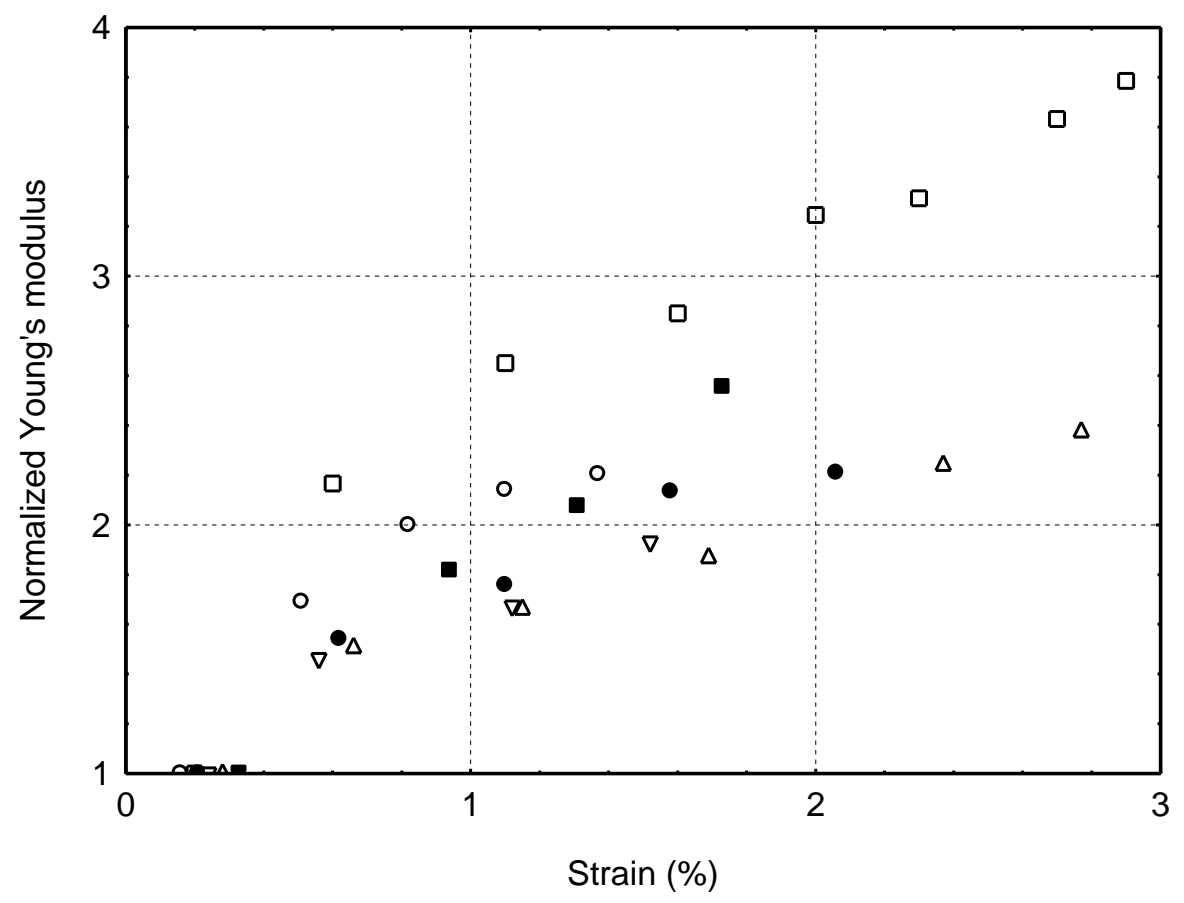

Figure 4: Normalized apparent Young's modulus as a function of fibre strain (each tested fibre is identified by a different symbol), clearly showing that the stiffness increases as a function of fibre strain. 
a.

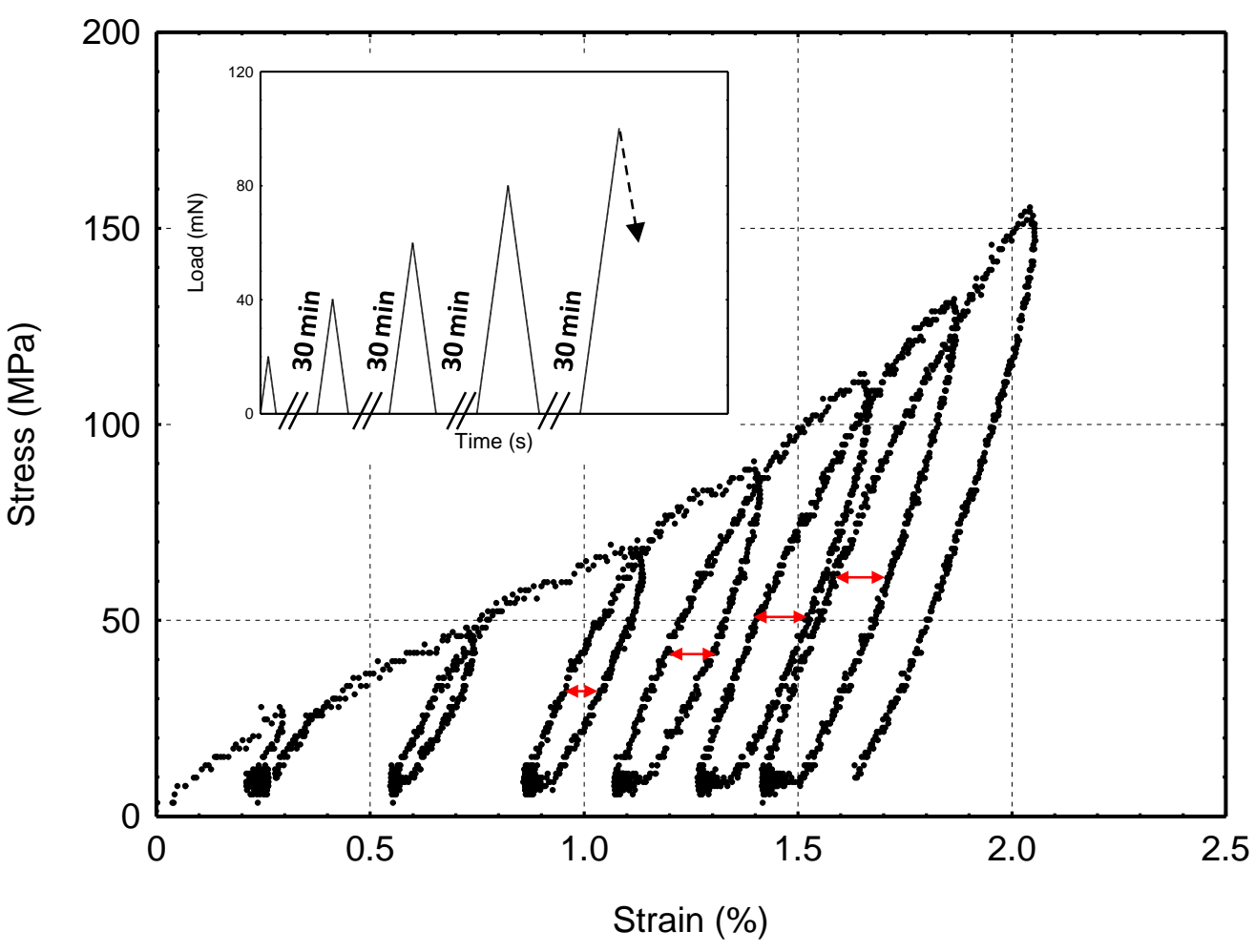

b.

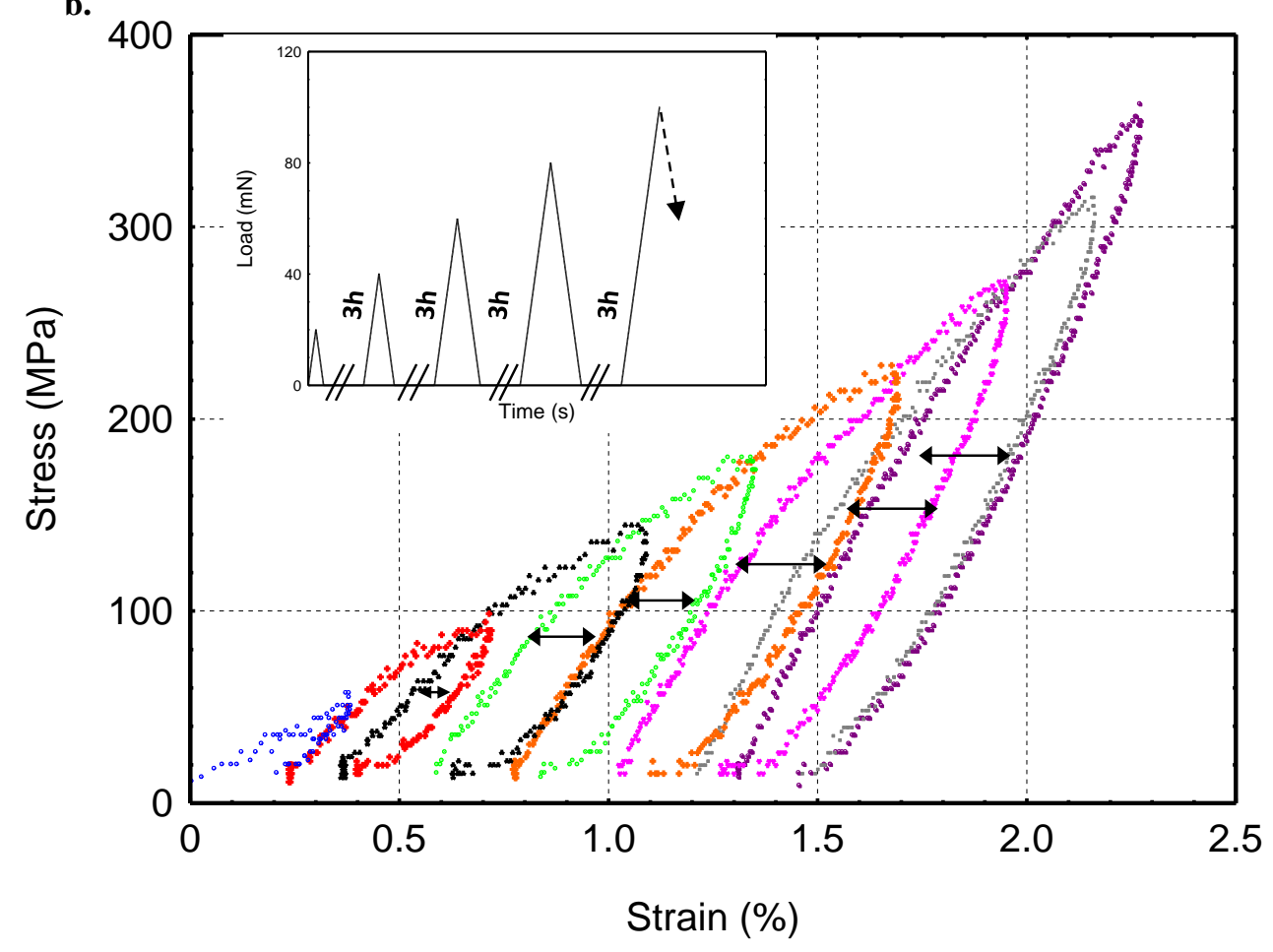

Figure 5: Stress-strain curves of repeated progressive tensile loading, with a load release between each cycle. (DMA; fibre length: $10 \mathrm{~mm}$; load feedback). a. Load release time: $30 \mathrm{~min}$. b. Load release time: 3 h. 


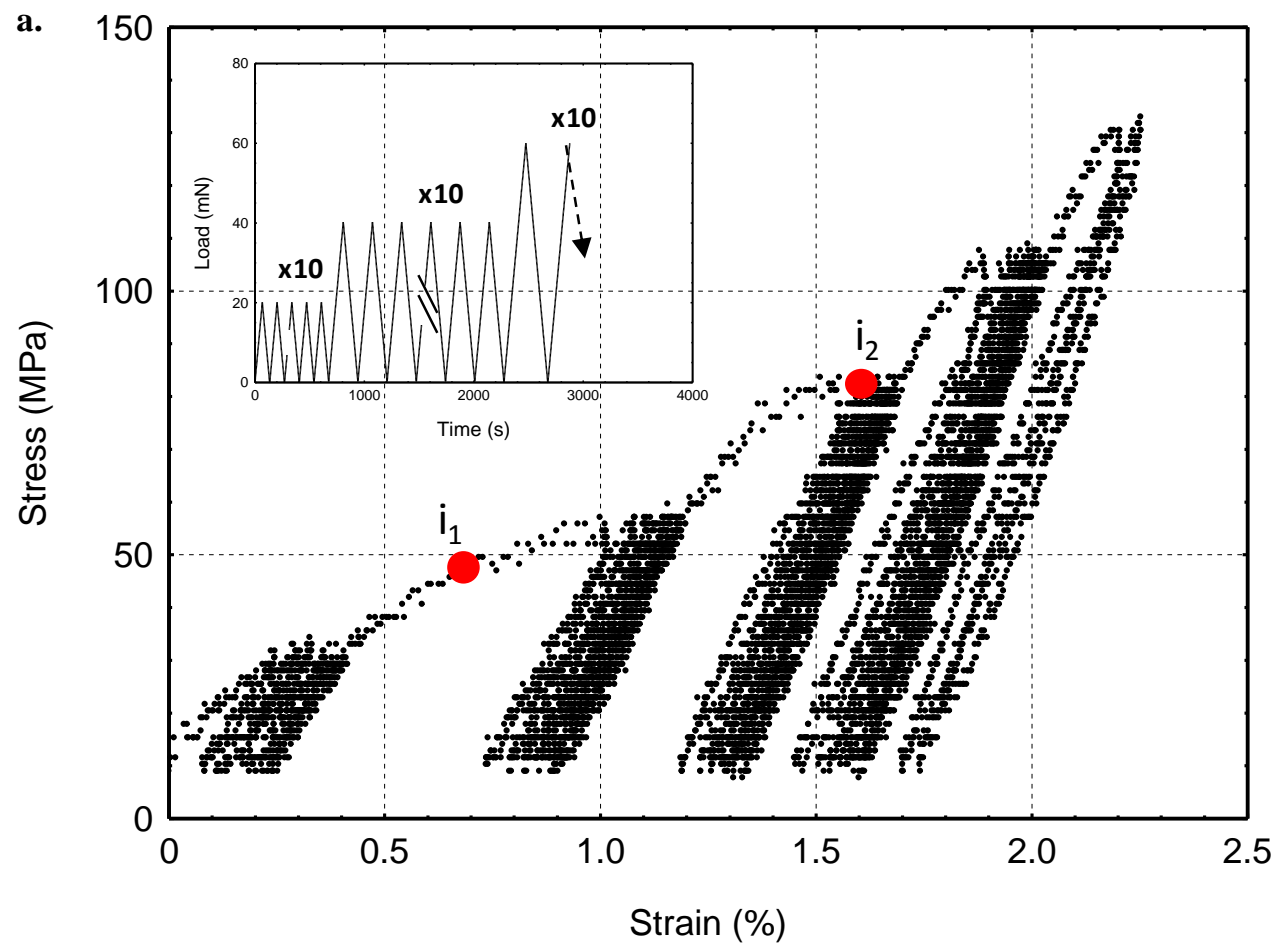

b.

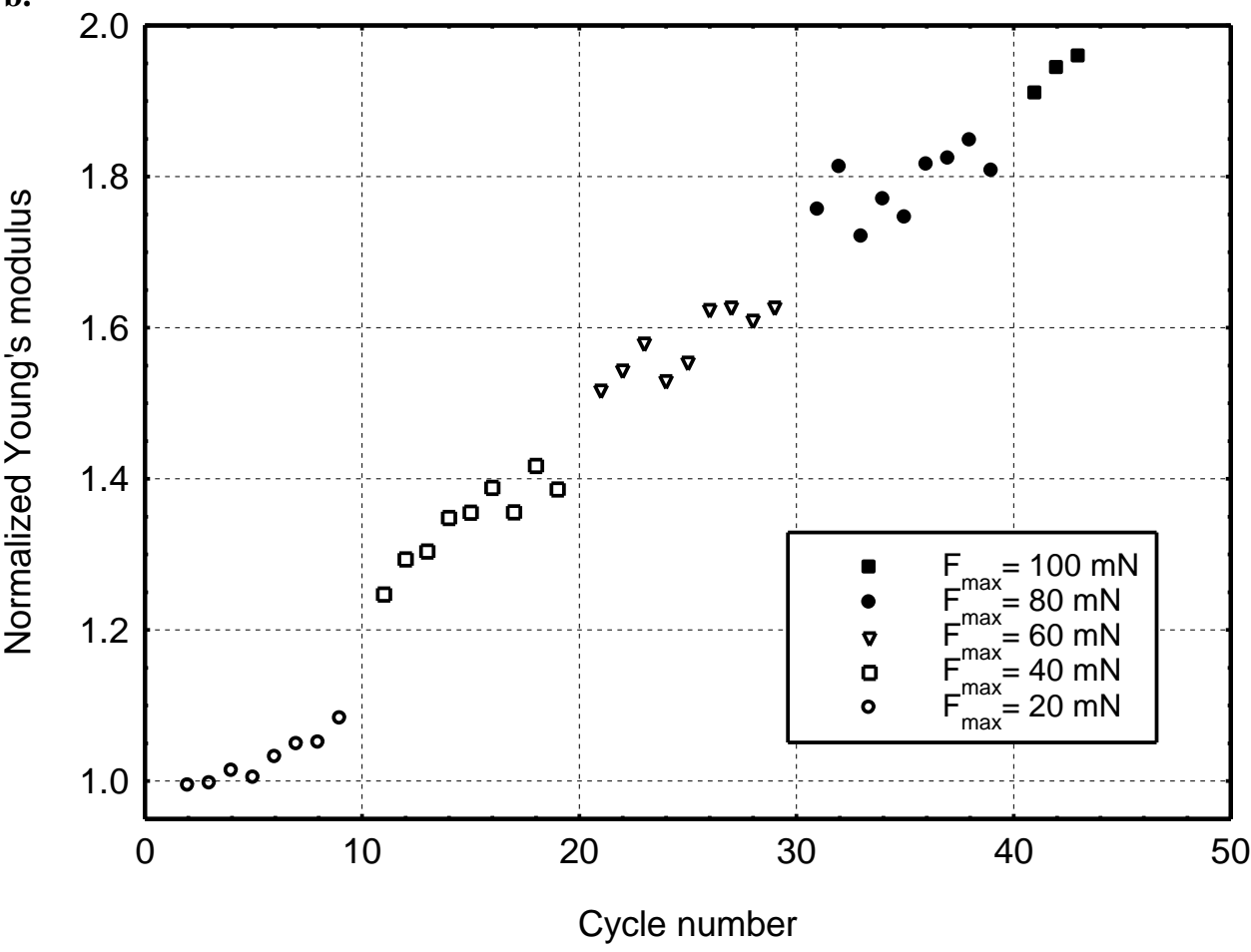

Figure 6.a. Progressive tensile loading of an elementary hemp fibre, with cycling at each loading step. b. Evolution of the normalized Young's modulus as a function of cycle number, for each of the five loading steps. (DMA; fibre length: $10 \mathrm{~mm}$; load feedback). 
a.

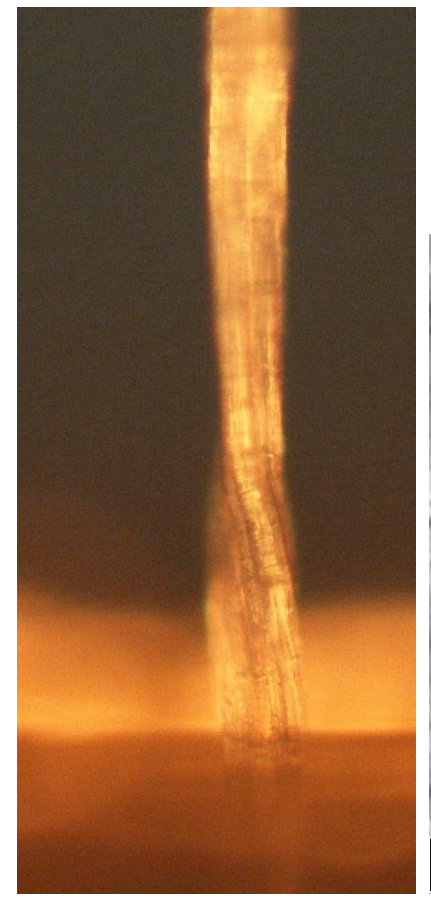

b.

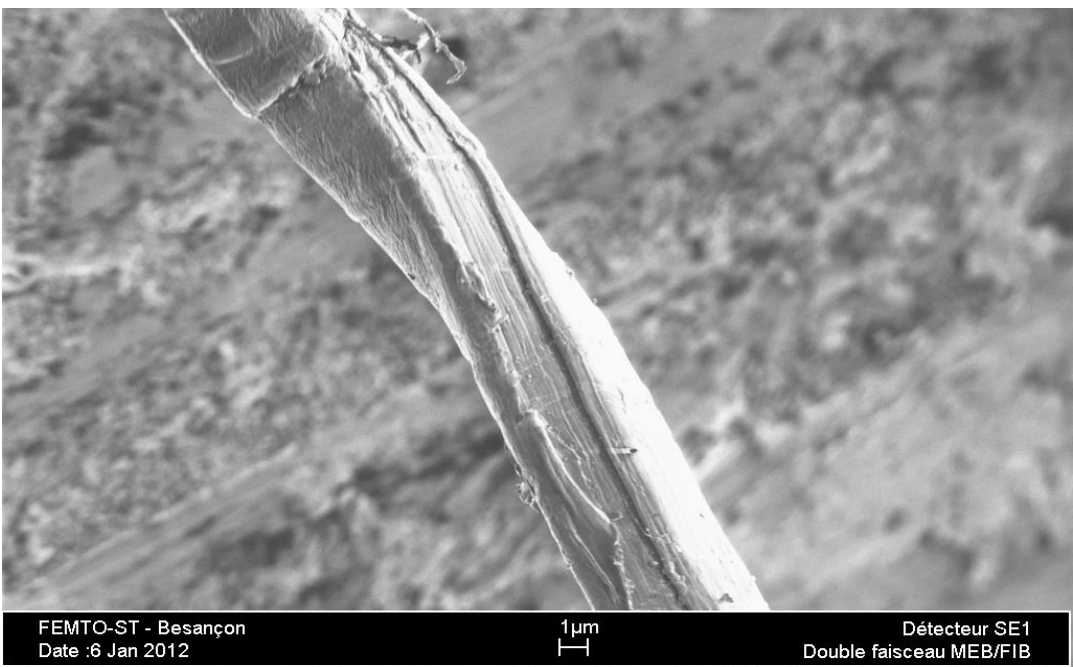

Figure 7: Images of hand-twisted fibres, using polarised light microscopy (a) and scanning electron microscopy (b).

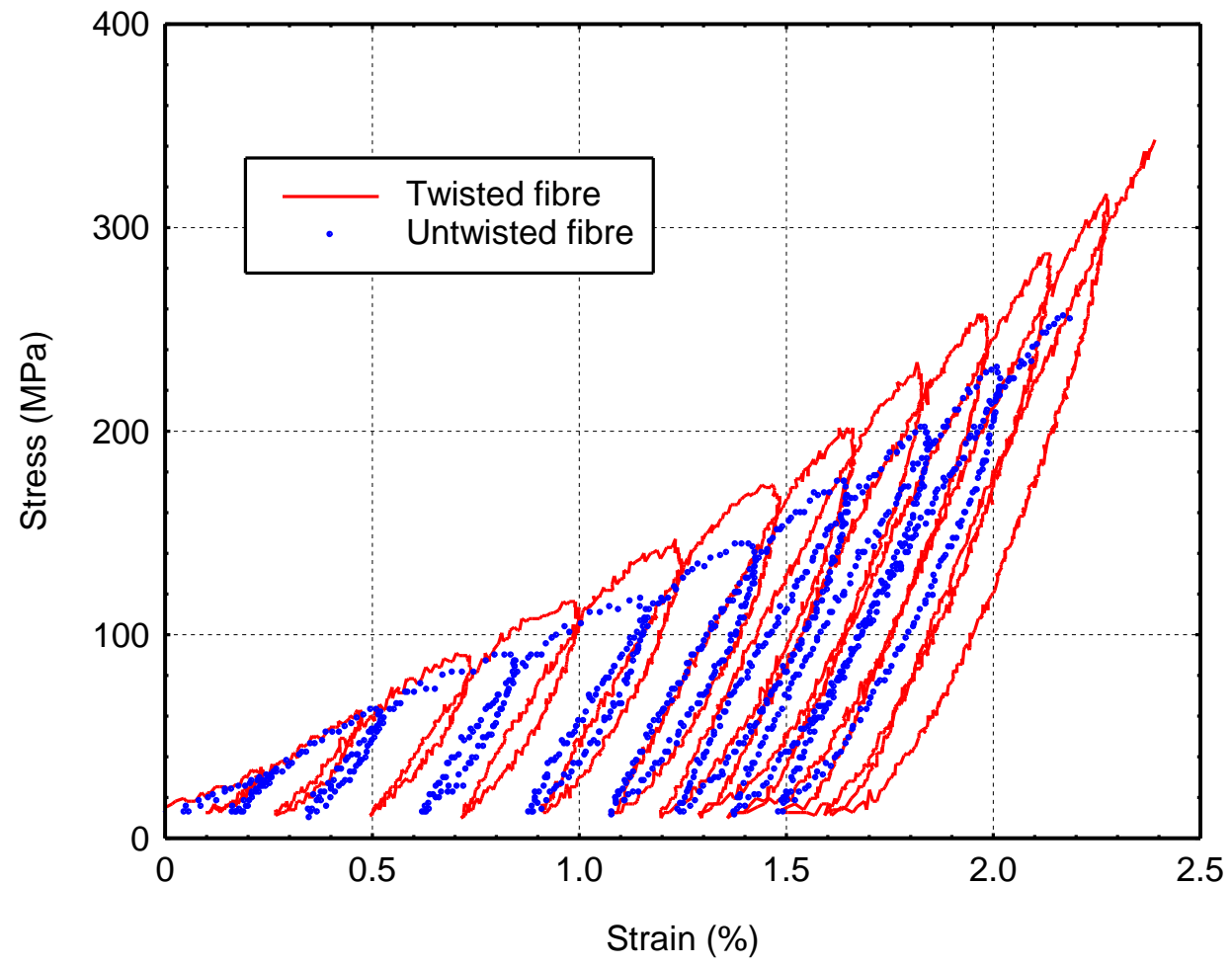

Figure 8: RPL of twisted and untwisted hemp fibres. 
a.

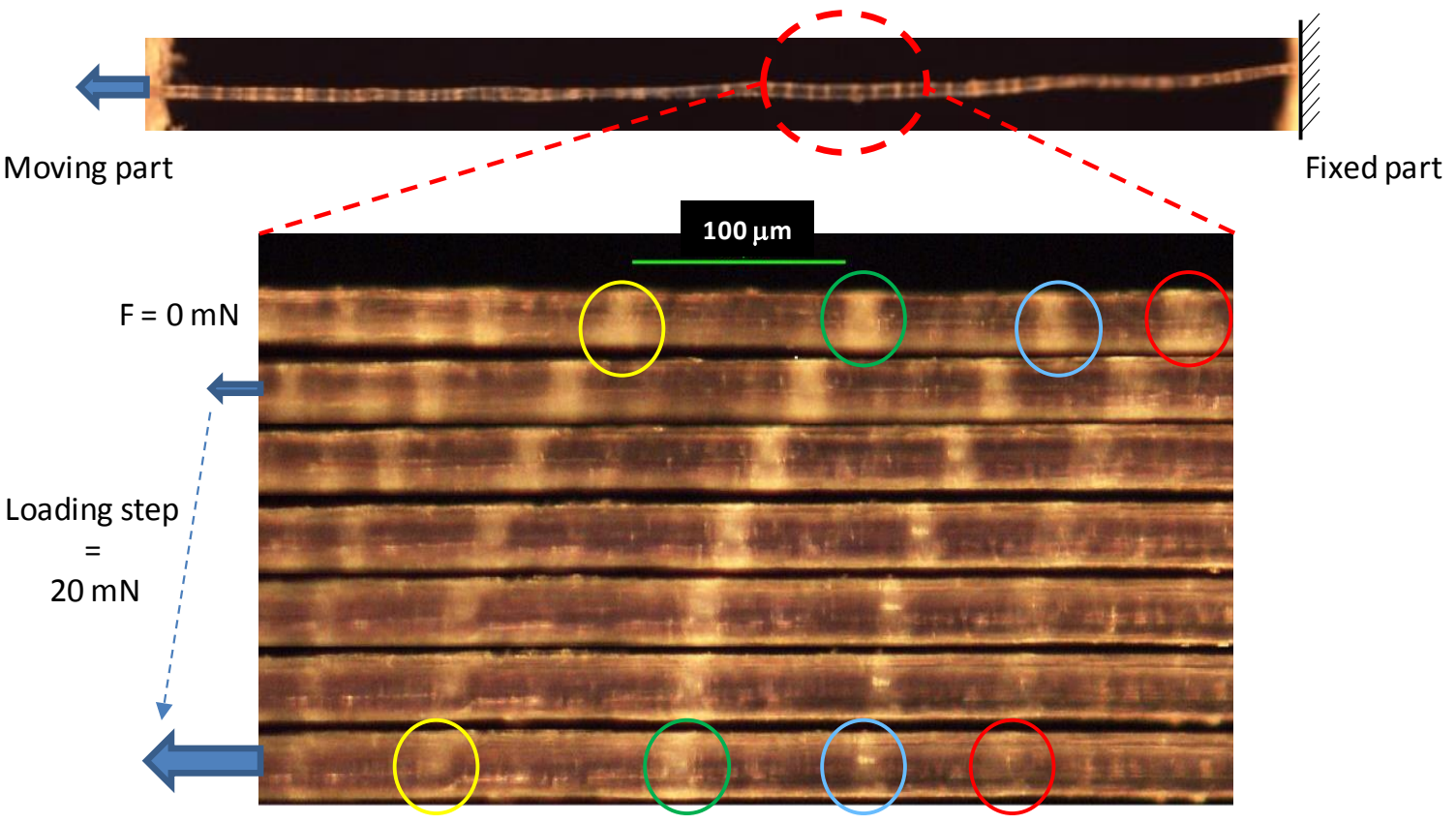

b.

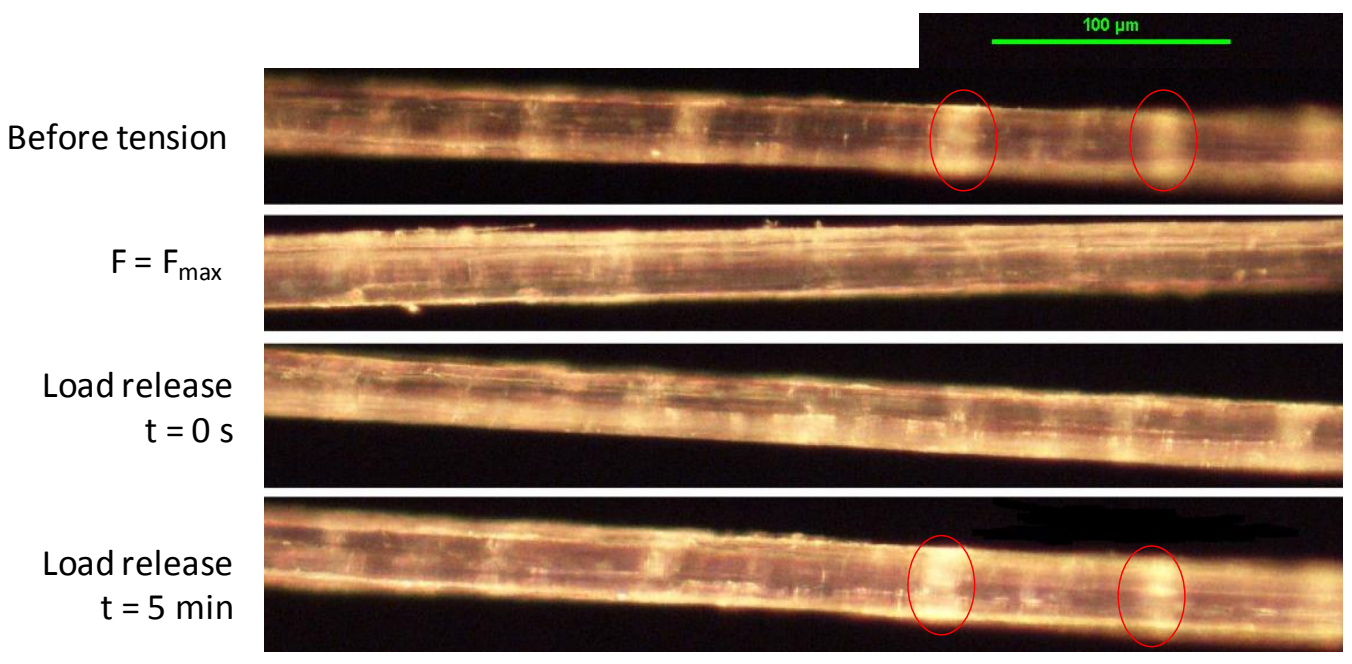

Figure 9.a. Successive images taken with polarized light microscopy during a RPL test.

b. Polarized light microscopy of a hemp fibre before and after the second inflection point $\left(i_{2}\right)$, and at two different times after tensile testing. 

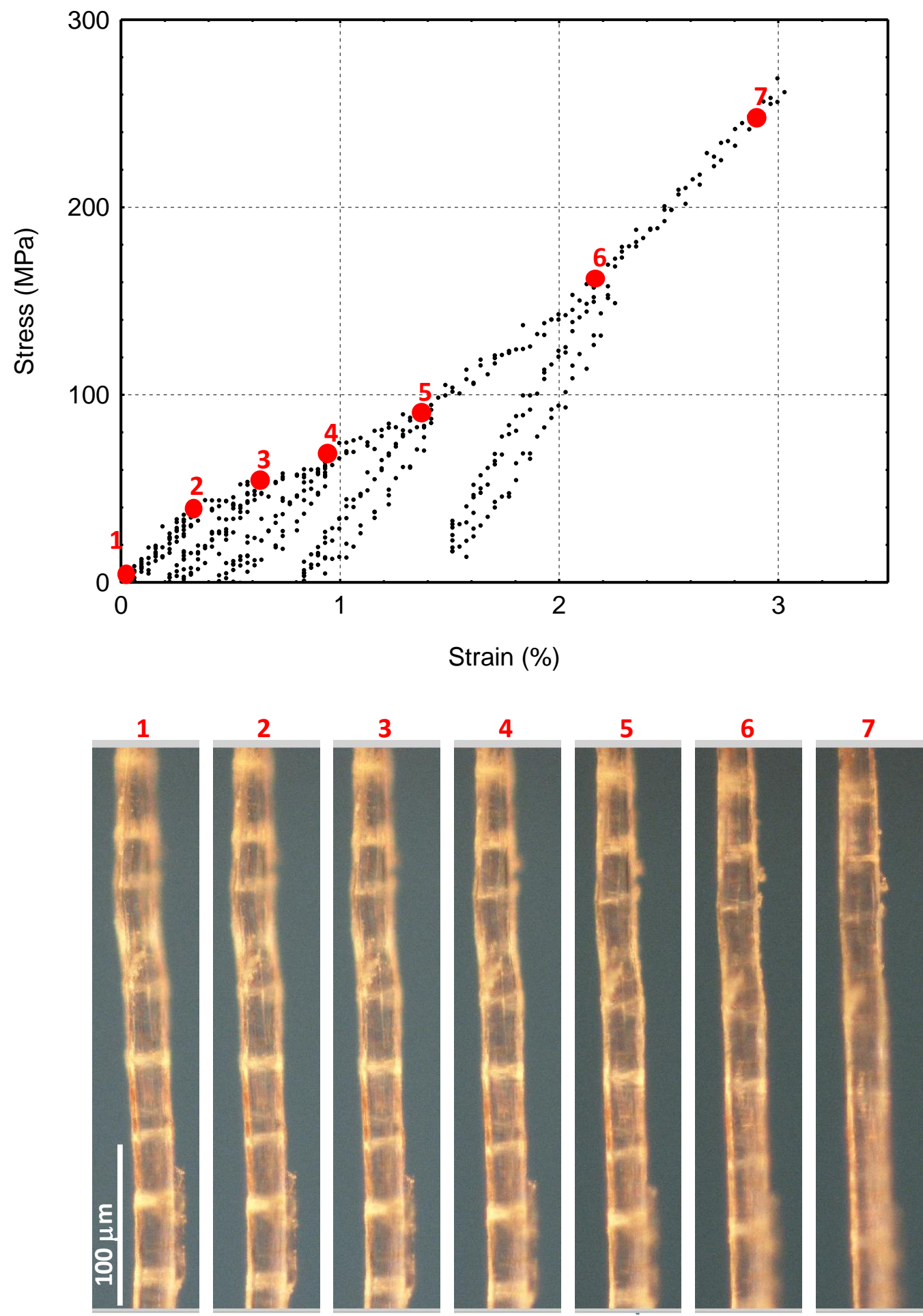

Figure 10: Series of polarized light microscopy images, showing that during tensile testing of a hemp fibre, the fibre dislocations gradually disappear, at stress levels beyond the second inflection point ( $i_{2}$ ) (corresponding to image $n^{\circ}$ 5) (Home-made micro-tensile stage; fibre length: $3 \mathrm{~mm}$; displacement feedback). 

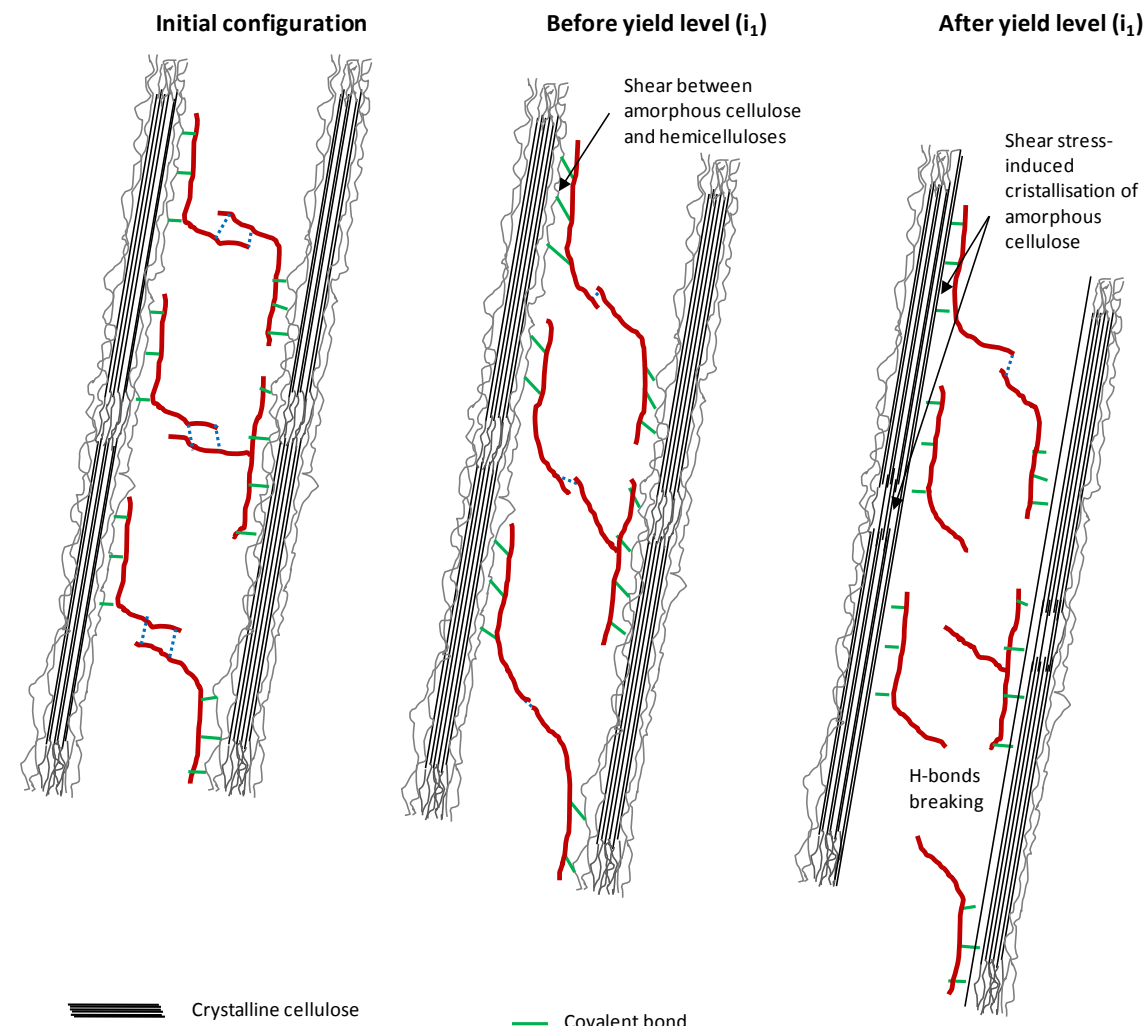

After yield level $\left(i_{1}\right)$

After inflection point $\left(\mathrm{i}_{2}\right)$
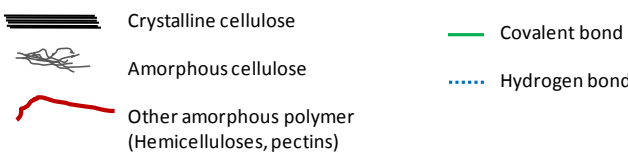

....... Hydrogen bond (Hemicelluloses, pectins)

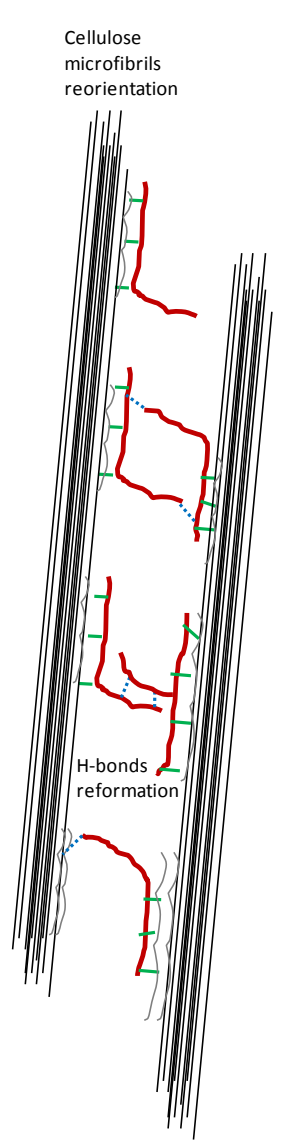

Figure 11: Schematic representation of the scenario proposed to explain the complex tensile behaviour of hemp fibre 
Table 1. Residual strain recovery as a function of cycle number, for an RPL test with $3 \mathrm{~h}$ of load release between each cycle.

\begin{tabular}{|c|c|c|c|}
\hline Cycle number & $\begin{array}{l}\text { Cumulated residual } \\
\text { strain at the end of } \\
\text { the unloading } \\
\text { phase (\%) }\end{array}$ & $\begin{array}{l}\text { Cumulated residual } \\
\text { strain after pause } \\
\text { time }(\%)\end{array}$ & $\begin{array}{l}\text { Strain recovery } \\
(\%)\end{array}$ \\
\hline 1 & & 0.242 & 0.032 \\
\hline 2 & 0.396 & 0.364 & 0.041 \\
\hline 3 & 0.628 & 0.587 & 0.06 \\
\hline 4 & 0.835 & 0.775 & 0.07 \\
\hline 5 & 1.095 & 1.025 & 0.047 \\
\hline 6 & 1.261 & 1.214 & 0.135 \\
\hline 7 & 1.450 & 1.315 & 0.124 \\
\hline 8 & 1.453 & 1.306 & \\
\hline
\end{tabular}

Table 2. Evolution of the fibre's rigidity during loading and unloading, with $3 \mathrm{~h}$ of load release between each cycle, as a function of sequential cycle number. The apparent Young's modulus during the loading and unloading steps is determined using the first linear part of the loading and unloading curves.

\begin{tabular}{|c|c|c|c|c|}
\hline Cycle number & $\begin{array}{c}\text { E-modulus } \\
\text { Loading step } \\
\mathrm{MPa}\end{array}$ & $\begin{array}{c}\text { E-modulus } \\
\text { Unloading step } \\
\mathrm{MPa}\end{array}$ & $\begin{array}{c}\text { Stiffness } \\
\text { increase (\%) }\end{array}$ & $\begin{array}{c}\text { Stiffness decrease between } \\
\text { unloading of cycle } \mathrm{n} \text { and loading } \\
\text { of cycle } \mathrm{n}+1 \\
(\%)\end{array}$ \\
\hline 1 & 20760 & 28920 & & \\
\hline 2 & 22220 & 30730 & 139 & 0.8 \\
\hline 3 & 25140 & 37230 & 178 & 23.4 \\
\hline 4 & 30440 & 40890 & 195 & 18.2 \\
\hline 5 & 35020 & 41630 & 199 & 14.4 \\
\hline 6 & 40220 & 45120 & 216 & 3.4 \\
\hline 7 & 42840 & 48440 & 232 & 5.1 \\
\hline 8 & & & & \\
\hline
\end{tabular}

Table 3. Stiffening of twisted and untwisted fibres during an RPL test.

\begin{tabular}{|c|c|c|}
\hline Cycle number & $\begin{array}{c}\text { Normalized E-modulus of } \\
\text { untwisted fibre }\end{array}$ & $\begin{array}{c}\text { Normalized E-modulus of twisted } \\
\text { fibre }\end{array}$ \\
\hline 1 & 1 & 1 \\
\hline 2 & 1.12 & 1.24 \\
\hline 3 & 1.39 & 1.41 \\
\hline 4 & 1.41 & 1.48 \\
\hline 5 & 1.58 & 1.63 \\
\hline 6 & 1.72 & 1.73 \\
\hline 7 & 1.94 & 1.83 \\
\hline 8 & 1.99 & 1.95 \\
\hline 9 & Failure & 2.19 \\
\hline 10 & & 2.29 \\
\hline
\end{tabular}


Table 4. Possible scenario describing the various mechanisms contributing to the multiple nonlinearities of the stress-strain curve of hemp fibre.

\begin{tabular}{|c|l|l|}
\hline $\begin{array}{c}\text { Segment } \\
\text { (point) of the } \\
\text { stress-strain } \\
\text { curve }\end{array}$ & Observations & Possible mechanisms \\
\hline I & $\begin{array}{l}\text { Quasi-linear behaviour with } \\
\text { slightly irreversible strain. }\end{array}$ & $\begin{array}{l}\text { Elastic deformation of the cellulose } \\
\text { microfibrils and amorphous } \\
\text { polymers. } \\
\text { Slight rotation of the microfibrils } \\
\text { towards a more parallel orientation. }\end{array}$ \\
\hline $\mathrm{i}_{1}$ & Yield level & $\begin{array}{l}\text { Matrix flow threshold: bonds break } \\
\text { in the amorphous matrix. }\end{array}$ \\
\hline II & $\begin{array}{l}\text { Apparent decrease in fibre' } \\
\text { stiffness. } \\
\text { Quasi-linear behaviour, with } \\
\text { significant irreversible } \\
\text { deformations and fibre } \\
\text { stiffening when the load is } \\
\text { released or the fibre is re- } \\
\text { loaded. }\end{array}$ & $\begin{array}{l}\text { Viscous flow of the amorphous } \\
\text { components under shear strain and } \\
\text { lock-in at a new position. } \\
\text { Stress-induced crystallization of } \\
\text { the para-crystalline cellulose. } \\
\text { Spiral spring-like extension of the } \\
\text { cellulose microfibrils in the } \\
\text { amorphous matrix. }\end{array}$ \\
\hline $\mathrm{I}_{2}$ & Inflection point. & $\begin{array}{l}\text { Maximum flow point of the matrix. } \\
\text { Crystallisation saturation point. }\end{array}$ \\
\hline III & Quasi-linear or parabolic. & $\begin{array}{l}\text { Deployment of cellulose } \\
\text { microfibrils in dislocation areas. } \\
\text { Decrease of the mean MFA. } \\
\text { Interfacial rupture between } \\
\text { crystalline cellulose and the } \\
\text { amorphous matrix. }\end{array}$ \\
\hline
\end{tabular}

